\title{
Reconstruction of Nasal Subunits using Anasolabial Flap: Case Report
}

\author{
Elsy Montúfar Cervera ${ }^{1, *}$, Antonio Ugalde Vitelly ${ }^{2}$, and Beatriz Kushida Contreras ${ }^{3}$ \\ ${ }^{1}$ Postgraduate Resident, Department of Plastic and Reconstructive Surgery, Autonomous University of Mexico, Mexico \\ ${ }^{2}$ Plastic Surgeon, Head of Plastic Surgery Service, General Hospital of Mexico, Mexico \\ ${ }^{3}$ Plastic Surgeon, Department of Plastic Surgery Service, General Hospital of Mexico, Mexico
}

*Corresponding author: Elsy Montúfar Cervera, Postgraduate Resident, Department of Plastic and Reconstructive Surgery, Autonomous University of Mexico, Mexico, Tel: 554135 2520; E-mail: elsy_1511@hotmail.com

Received: 13 Nov, 2020 | Accepted: 24 Nov, 2020 | Published: 30 Nov, 2020

Citation: Cervera EM, Vitelly AU, Contreras BK (2020) Reconstruction of Nasal Subunits using Anasolabial Flap: Case Report. J Surg Open Access 7(1): dx.doi.org/10.16966/2470-0991.229

Copyright: ( 2020 Cervera EM, et al. This is an open-access article distributed under the terms of the Creative Commons Attribution License, which permits unrestricted use, distribution, and reproduction in any medium, provided the original author and source are credited.

\section{Abstract}

Nasal reconstruction is a broad and diverse topic that encompasses multiple scenarios as well as various repair techniques. The ala nasi is considered a cosmetic unit that represents a challenge for the surgeon, both in its functional and aesthetic reconstruction.

Local and regional flaps allow reconstruction of multiple defects, thus restoring form and function. The classic method for reconstruction of the ala nasi is repair using a nasolabial flap. This flap has specific characteristics in terms of location, size, circulatory pattern, vascularization, innervation and function.

This article presents the case of a 22-year-old male patient with traumatic nasal injury, with loss of continuity predominantly in the left ala nasi. Using a nasolabial flap for reconstruction.

Keywords: Nasal reconstruction; Ala nasi; Nasolabial flap

\section{Introduction}

Between 1950 and 1960, several regional flaps with axial patterning, were described. McGregor and Bakamjian, developed a large variety of flaps in the acreages to head and neck, including the nasolabial flap. Later, in 1956 González Ulloa described the aesthetic units and subunits into which the face is divided; by 1966 Mildred determined regional units for the nose; and in 1985 Burget and Menick defined them in greater detail and described how to repair other areas of the face.

The nasal area is anatomically complex, for its comprehensive reconstruction an integral understanding is necessary, this being a three-dimensional structure with its bone and cartilaginous support, a mucous lining and a skin covering, and according to the condition of these structures it is the surgical and reconstructive challenge to face. The general principles of reconstruction are also applicable to the nasal area as long as we understand and respect the nasal units and subunits [1-3].

The nasal reconstruction is a very extensive topic, comprising many situations and various techniques of restoration, which depend on: the etiology (traumatic, neoplastic or congenital), the idiosyncrasies of the patient (age, gender, race), comorbidities (diabetes mellitus, smoking, etc.), the location of the defect (tip, back or alanasae), the size and depth of the lesion (superficial, localized, subtotal, total or extended loss of substance) $[4,5]$.
Various methods have been used in nasal reconstruction, ranging from dermal regeneration (integra) [6], skin grafts, as well as a wide variety of flaps; The nasolabial flap, frontal flap and the frontonasal flap are recognized as the main pillars in nasal reconstruction [7].

The frontonasal flap was described by Riege in 1967 as a random pattern transposition skin flap of the glabella and nasal dorsum based on one side of the nose and used to cover tip defects up to 2 $\mathrm{cm}$ in diameter, however defects in the alar margin, scarring and flap contraction can cause significant alar retraction [8].

For the reconstruction of the alanasae, the frontal and nasolabialflaps provide an excellent option when they are performed in more than one stage given the similarity in the coloration of the skin in that area, as well as the proximity to the lesion [9], but it is still arguable whether excellent results can be achieved in a single stage.

The nasolabial flap is located on the nasolabial fold, it can be designed with a dimension of $2 \times 5 \mathrm{~cm}$, and corresponds to a type $\mathrm{C}$ fasciocutaneous pattern.

Its dominant pedicle originates from the angular artery, the terminal branch of the facial artery, with a length of $1 \mathrm{~cm}$ and about $0.5 \mathrm{~mm}$ in diameter. It is located in the lateral region of the oral commissure, between the orbicularis oculi muscles and the levator labia [10]. It can be used with a distal or proximal pedicle (Figure 1). 


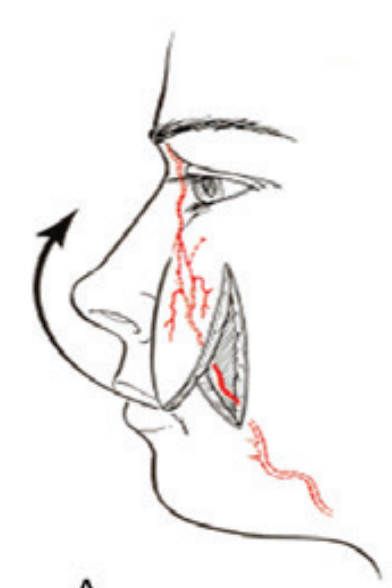

A

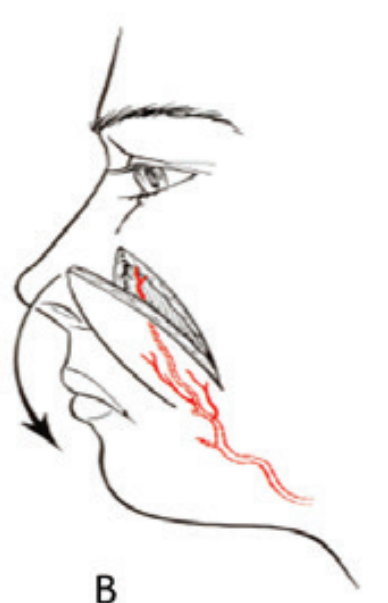

B

Figure 1: A) Of superior pedicle; B) Of inferior pedicle [11].

\section{Clinical Case}

This is a 22-year-old male patient, who presented traumatic injury due to aggression by third parties, with a sharp object, with a main condition in the left facial region, predominantly in the ipsilateral alanasae (Figure 2).

Debridement of the affected and devitalized areas is carried out, the left alanasae being affected mainly with compromise of the rim, being able to preserve the soft triangle; creating the design of a nasolabial flap lower base over the nasogenian groove, with dimensions of $2 \mathrm{~cm}$ long and $1.5 \mathrm{~cm}$ wide (Figure 3), carrying out during the first surgical time, the lifting of the nasolabialflap, fasciocutaneous, respecting the underlying musculature.

After the first surgical reconstruction of the alanasae and retaining the soft triangle is obtained recreating the continuity of the rim nasal by thinning and plication of the distal portion of the flap (Figure 4).

After the first reconstruction stage and a 3 weeks' time, the second surgical phase is planned to carry out the release of the flap and refine its inset (Figure 5).

Subsequently, a 6-month postoperative follow-up was carried out, showing the final result of the flap (Figures 6-8).

\section{Discussion and Conclusion}

Nasal reconstruction, and in particular alanasae reconstruction, is always a challenge for the plastic surgeon. This is a complex anatomical subunit of the nose. It comprises three thin layers and a bilaminar convexity. Has an intact structure, as well as important anatomical limits, such as the alar notch, nasolabial channel and narinario orifice, therefore the preservation of these structures is the balance of the central facial cosmetic $[11,12]$.

Numerous options have been used for alanasae reconstruction, including skin grafts, local flaps, pedicle flaps, perforator-based flaps, and even free flaps [7].

Local flaps from the immediate proximity to the defect are the most desirable, both from an aesthetic and functional point of view. However, recently, use has been made of perforator flaps of the nasal lateral artery which can be carried out in a single surgical stage, however, with a meticulous microsurgical technique as well as with the needed microsurgical equipment.

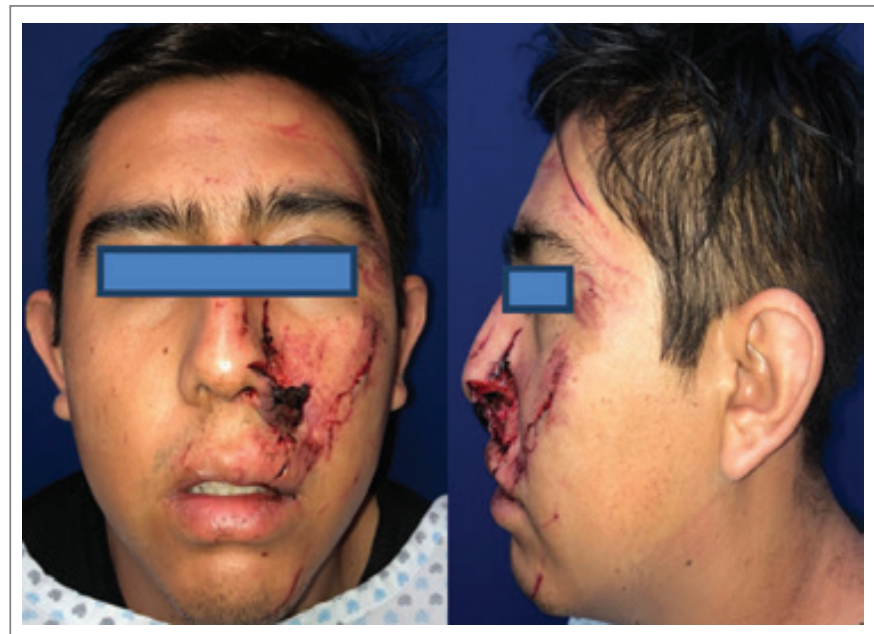

Figure 2: Front and side view.
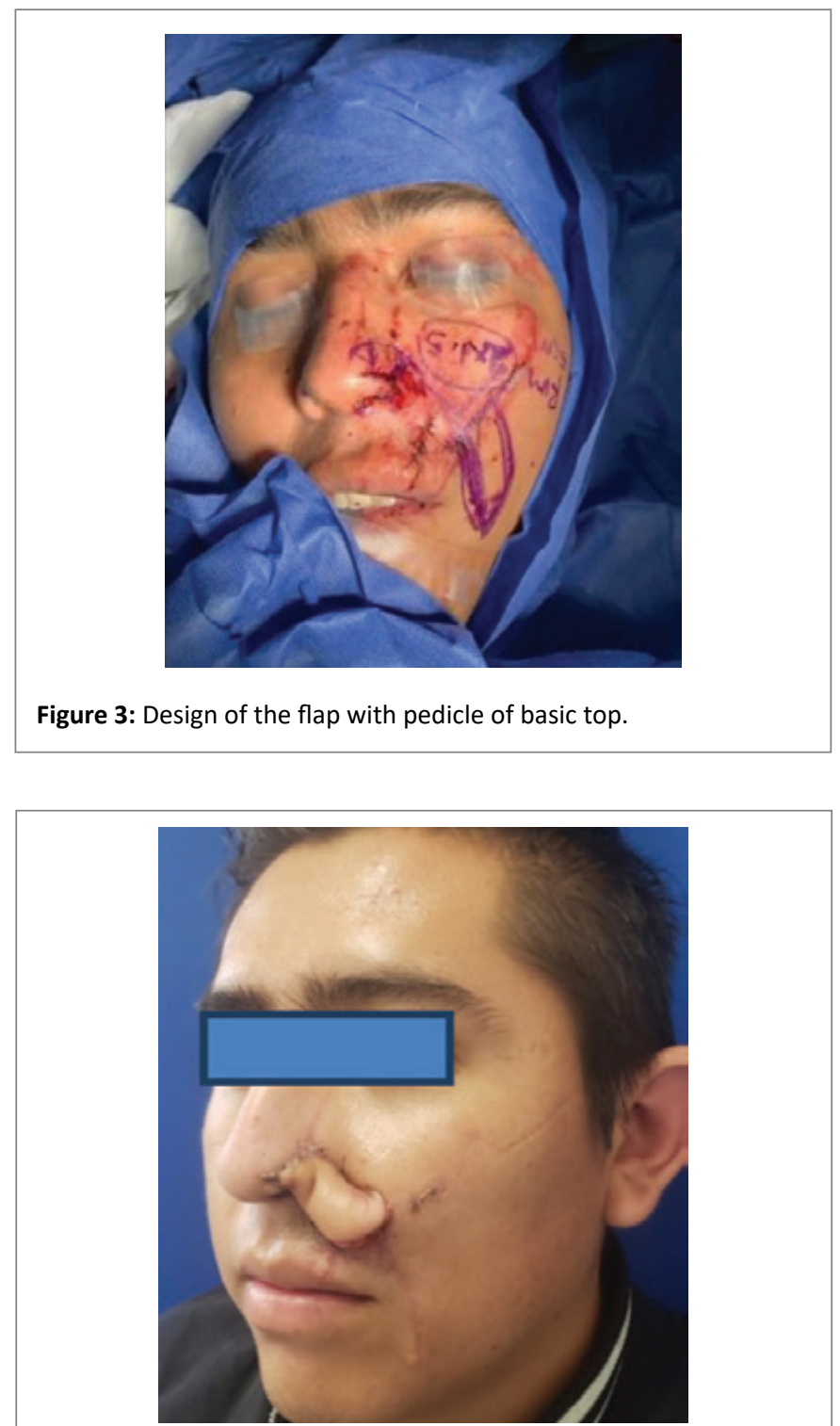

Figure 4: Oblique view, first surgical stage. 


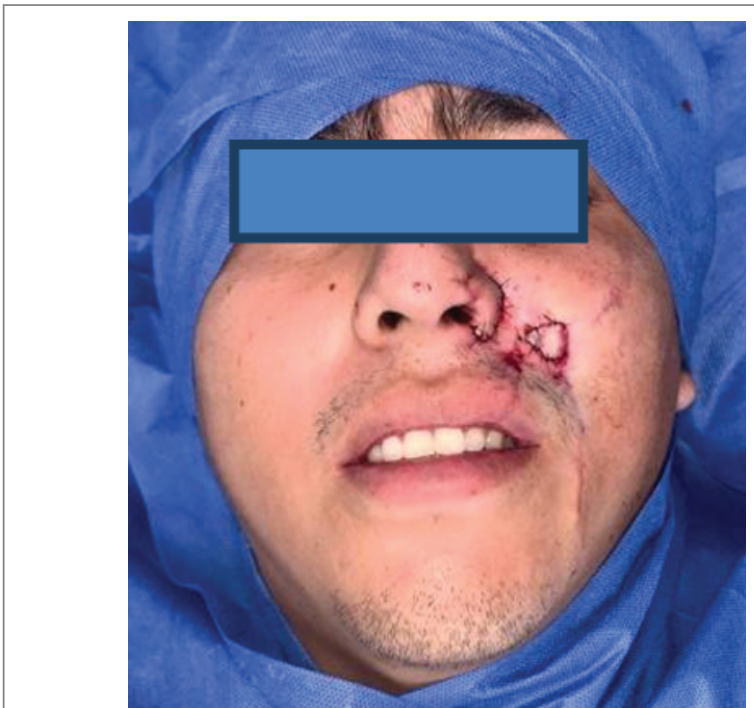

Figure 5: Flap release. Second surgical stage.

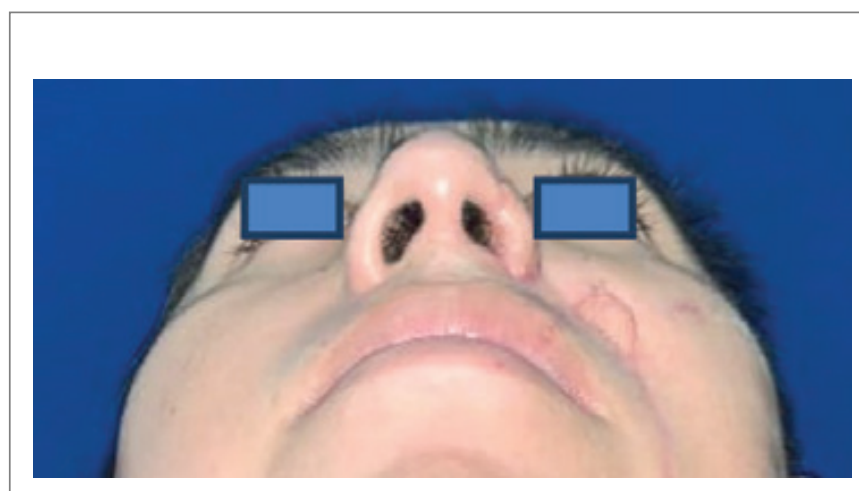

Figure 6: Final result. Basal view.

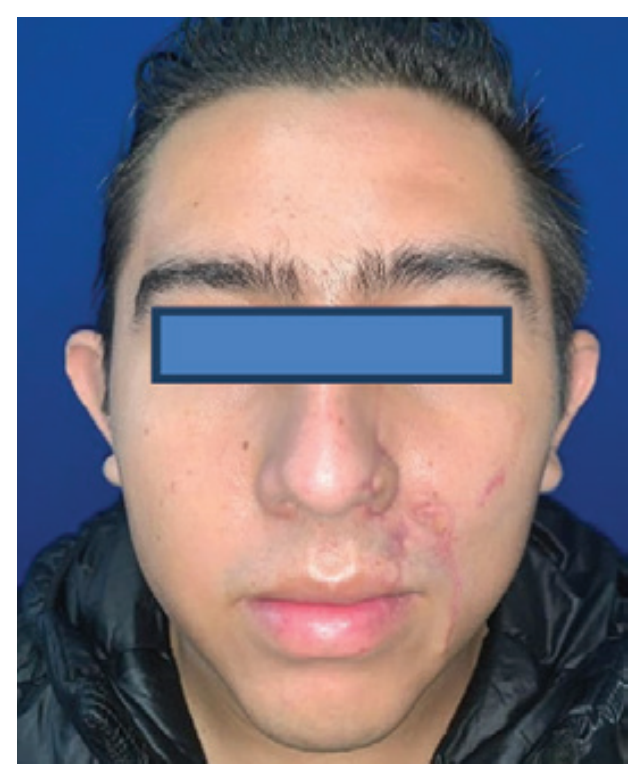

Figure 7: Final result. Front view.

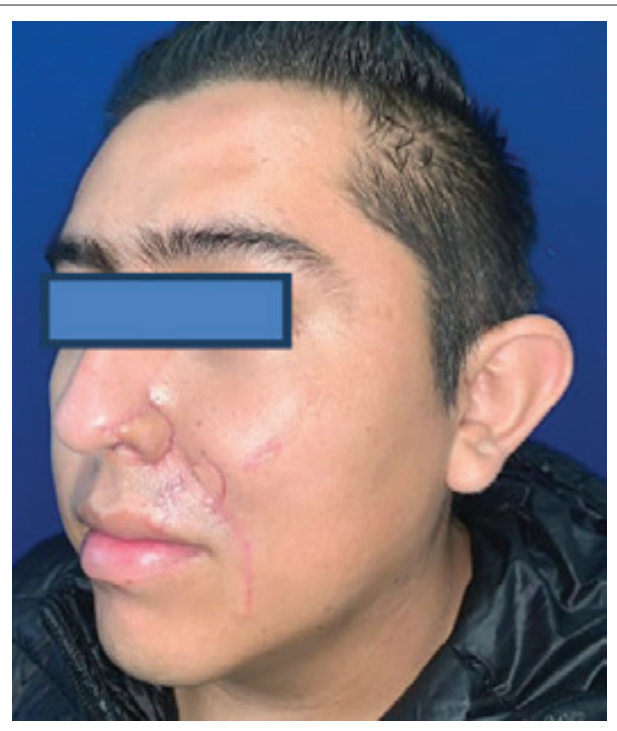

Figure 8: Final score. Oblique view.

In our case, the patient was treated with antibiotic prophylaxis, and later underwent surgery for the reconstructive process of 2 surgical stages using a nasolabial flap.

It was sought preserve as far as possible nasal cosmetic units described by Gonzales Ulloa, and seeking to place scars on natural lines.

In conclusion, coverture given by the nasolabial flap, fulfills the purpose of an adequate aesthetic and functional result, low morbidity of the donor area, making it a flap of choice for this particular type of nasal reconstruction.

\section{References}

1. Rezaeian F, Corsten M, Haack S, Gubisch W, Fischer H (2016) Nasal Reconstruction: Extending the Limits. Plast Reconstr Surg Glob Open 4: e804.

2. Zelken JA, Reddy SK, Chang C, Chuang S, Chang C, et al. (2017) Nasolabial and forehead flap reconstruction of contiguous alarupper lip defects. J Plast Reconstr Aesthet Surg 70: 330-335.

3. Hu X, Zeng G, Zhou Y, Sun C (2017) Reconstruction of Skin Defects on the Mid and Lower Face Using Expanded Flap in the Neck. J Craniofac Surg 28: e137-e141.

4. Alp E, Leman D, Demiroz A (2020) Nasolabial Perforator Flap: A Multi-Tool for Reconstruction of Facial Units. J Craniofac Surg 31: 1042-1045.

5. Zielinski T (2010) The primary closure approach of dog bite injuries of the nose. Otolaryngol Pol 64: 157-160.

6. Seth AK, Ratanshi I, Dayan JH, Disa JJ, Mehrara BJ (2019) Nasal Reconstruction Using the Integra Dermal Regeneration Template. Plast Reconstr Surg 144: 966-970.

7. Ashley T, James A, Gore S, Aldred R (2014) Use of the nasal sidewall island inversion flap for single-stage ala nasi reconstruction: a report of 103 consecutive cases. Plast Reconstr Surg 133: 377-385.

8. Scheufler O (2016) Variations in Frontonasal Flap Design for SingleStage Reconstruction of the Nasal Tip. Plast Reconstr Surg 138: 1032e-1042e. 
9. Godoy-Gijón E, Palacio-Aller L, González-Sabin M (2015) Reconstruction of the ala nasi using a malar turnover is landpedicle flap. Actas Dermosifiliogr 106: 233-235.

10. Patel AA, Cheng A (2019) The Nasolabial Flap. Atlas Oral Maxillofac Surg Clin North Am 19: 1061-1067.

11. Mathes SJ, Stevenson TR (1988) Regional Flaps: anatomy and basic techniques. Head and neck. Am J Surg 156: 248-251.

12. Shenaq SM, Dinh TA, Spira M (1989) Nasal alar reconstruction with an ear helix free flap. J Reconstr Microsurg 5: 63-67. 